\title{
Heterogeneity of PTEN and PPAR- $\gamma$ in cancer and their prognostic application to bladder cancer
}

\author{
ZHOUZHOU ZHANG ${ }^{1 *}$, HUAN XU $^{2 *}, \mathrm{JIN} \mathrm{JI}^{2^{*}}$, XIAOLEI SHI ${ }^{2}, \mathrm{JI} \mathrm{LYU}^{2}$, \\ YASHENG ZHU ${ }^{2}$, HONGQI YU ${ }^{1}$ and FUBO WANG ${ }^{2}$ \\ ${ }^{1}$ Department of Urology, North District of Suzhou Municipal Hospital, Suzhou, Jiangsu 215000; ${ }^{2}$ Department of Urology, \\ Shanghai Changhai Hospital, Second Military Medical University, Shanghai 200000, P.R. China
}

Received March 18, 2018; Accepted July 8, 2019

DOI: $10.3892 /$ etm.2019.7879

\begin{abstract}
The aim of the present study was to determine the prognostic value of peroxisome proliferator-activated receptor- $\gamma$ (PPAR- $\gamma$ ) and phosphatase and tensin homologue deleted on chromosome ten (PTEN) for bladder cancer. Data were collected from The Cancer Genome Atlas (TCGA), a public database, and were analyzed to assess PTEN and PPAR- $\gamma$ heterogeneity as well as distinct trends in bladder cancers. Furthermore, PPAR- $\gamma$ and PTEN expression levels and their association with one another were evaluated. Finally, the prognostic significance of PPAR- $\gamma$ and PTEN for bladder cancer was validated in vivo using clinical samples. Based on the TCGA database, PTEN levels were significantly increased in bladder cancers $(\mathrm{P}<0.001)$; whereas PPAR- $\gamma$ expression was downregulated in the same samples $(\mathrm{P}<0.05)$. Furthermore, linear correlation analysis indicated that in bladder cancers, PPAR $-\gamma$ and PTEN are inversely correlated $(\mathrm{P}<0.001)$. The assessment and analysis of clinical samples revealed that PPAR- $\gamma$ was significantly elevated in tumor tissues $(\mathrm{P}<0.001)$; however, PTEN was downregulated in cancer tissues $(\mathrm{P}<0.001)$. Furthermore, PPAR- $\gamma$ expression determined by
\end{abstract}

Correspondence to: Dr Fubo Wang, Department of Urology, Shanghai Changhai Hospital, Second Military Medical University, 168 Changhai Road, Shanghai 200000, P.R. China

E-mail: wangbofengye@163.com

Dr Zhouzhou Zhang, Department of Urology, North District of Suzhou Municipal Hospital, 242 Guangji Road, Suzhou, Jiangsu 215000, P.R. China

E-mail: 5747096@qq.com

${ }^{*}$ Contributed equally

Abbreviations: TCGA, The Cancer Genome Atlas; PPAR- $\gamma$, peroxisome proliferator-activated receptor- $\gamma$; PTEN, phosphatase and tensin homologue deleted on chromosome ten; TURBT, transurethral resection of bladder tumors

Key words: bladder cancer, phosphatase and tensin homologue deleted on chromosome ten, peroxisome proliferator-activated receptor- $\gamma$, tissue heterogeneity immunohistochemistry grey level $(\mathrm{P}=0.002)$ was also elevated in high-grade and invasive bladder cancers compared with low-grade and superficial tumors, whereas PTEN levels exhibited the opposite in this analysis $(\mathrm{P}=0.001)$. In individuals with lymphoid metastasis, PPAR- $\gamma$ was significantly increased $(\mathrm{P}<0.001)$, and PTEN was significantly decreased $(\mathrm{P}<0.001)$. Pearson analysis revealed a significant negative correlation between PPAR- $\gamma$ and PTEN expression $(r=-0.604, \mathrm{P}<0.05)$. In conclusion, tissue heterogeneity was observed with respect to PPAR- $\gamma$ and PTEN expression in bladder cancer. PTEN and PPAR- $\gamma$ expression are negatively correlated and may be excellent indicators of bladder cancer tumorigenesis and progression.

\section{Introduction}

Bladder cancer is the fifth most common cancer worldwide. Most bladder cancers are not muscle-invasive and can generally be managed with only transurethral resection of bladder tumors (TURBT) and intravesical therapy (1). Patients with high-grade non-muscle-invasive bladder cancer may eventually develop muscle invasion, necessitating surgical management with radical cystectomy or additional therapies (2) relevant to bladder cancer detection and prognosis.

Although imaging is widely used clinically, its ability to predict clinical outcomes for patients with bladder cancer remains limited. Therefore, tumor marker expression is an important component of the prognosis; however, specific markers to detect bladder cancer have not yet been identified. In addition, the prognostic power of a single marker is limited; however, the identification of a combination of markers to predict bladder cancer outcomes may have greater prognostic significance. Previous data have implicated peroxisome proliferator-activated receptor- $\gamma(\operatorname{PPAR}-\gamma)$ and phosphatase and tensin homologue deleted on chromosome ten (PTEN) inactivation in the development of keratinizing squamous metaplasia, an important process driving malignancy in the intestinal tract (3). This process is also significant during urogenital differentiation, and previous studies using either embryonic urogenital epithelium or adult bladder urothelium have demonstrated that urothelium can be programed to form prostate-like acini $(4,5)$. A previous study identified specific molecular pathways activated during normal bladder 
development and urothelial response to injury (6). The molecular findings from these studies are relevant to malignant tumor development and describe potential novel markers that may have clinical utility.

The PPAR- $\gamma$ and PTEN pathways are important for maintaining cellular energy balance and during urothelial differentiation. PPAR- $\gamma$ is a type II nuclear receptor encoded by the PPAR- $\gamma$ gene in humans that regulates fatty acid and glucose metabolism, and PPAR- $\gamma$ activation appears to have important functions in various human cancer cell lines $(7,8)$. PTEN is a protein encoded by the PTEN gene, which has been identified to contain several cancer-causing mutations. It functions as a tumor suppressor gene through the activation of its phosphatase protein product. It is also commonly mutated in bladder disease (9), where it has an important role in regulating cell differentiation and tumorigenesis. It has previously been suggested that the PPAR- $\gamma$ agonist pioglitazone is associated with an increased risk for bladder cancer (10). PTEN inactivation has also been implicated in bladder cancer development, in which it synergizes with other genetic changes to drive tumorigenesis. Expression of these two markers exhibits tissue heterogeneity, and there are no reports at present examining the association between their expression and progression of bladder cancer.

In the present study, the expression levels of PPAR- $\gamma$ and PTEN protein in bladder cancer and the association between clinical parameters and PPAR- $\gamma$ and PTEN protein expression were examined.

\section{Materials and methods}

Patients. Patients were recruited from the North District of Suzhou Municipal Hospital (Suzhou, China) from January 2010 to January 2015. Tissues included in the analysis were taken from 94 patients, including 77 male patients and 17 female patients aged from 33 to 92 years old (mean, $71 \pm 11.22$ ), 60 of whom had received TURBT, whereas 34 were treated by partial cystectomy.

Applying the World Health Organization classification (2004) (11), tissues were classified as low-grade urothelial carcinoma (59 cases) and high-grade urothelial carcinoma (35 cases). Clinical classification was performed according to the Classification of Malignant Tumors (TNM) criteria; with superficial tumors (Ta-T1; $\mathrm{n}=61)$ and invasive tumors (T2-T4; $\mathrm{n}=33$ ). Lymphatic metastasis was present in 31 cases. A total of 20 normal bladder tissue samples were obtained as control samples from 13 male patients during radical prostatectomy and from 7 female patients during biopsy. All patients provided written informed consent and the present study was approved by Suzhou Municipal Hospital Ethics Committee.

Bioinformatics analysis. A public database, The Cancer Genome Atlas (TCGA) (https://cancergenome.nih.gov/) was employed for this study. In total, information of 994 patients were collected and the patients with incomplete information were excluded from this study. The gene expression was analyzed by SPSS software version 13.0 (SPSS, Inc.,) and GraphPad Software Version 5 (GraphPad Software, Inc.).

Immunohistochemistry (IHC). Tissues were fixed in $10 \%$ formalin at room temperature for $24-48 \mathrm{~h}$ and embedded in paraffin blocks. Sections (3-5 $\mu \mathrm{m})$ were prepared from paraffin blocks for staining. During immunohistochemical analysis, the sections were hydrated in graded alcohol dilutions. Following heat-mediated antigen retrieval, the sections were incubated with $3 \% \mathrm{H}_{2} \mathrm{O}_{2}$ for $15 \mathrm{~min}$ at room temperature and blocked with 5\% bovine serum albumin (cat. no. ST023; Beyotime Institute of Biotechnology, Haimen, China) for $1 \mathrm{~h}$ at room temperature. Sections were subsequently incubated with primary antibodies overnight at $4^{\circ} \mathrm{C}$ followed by secondary antibody incubation for $1 \mathrm{~h}$ at room temperature. The primary antibodies used were rabbit anti-PPAR- $\gamma$ antibody (1:200; cat. no. ab209350; Abcam, Cambridge, UK) and rabbit anti-PTEN antibody (1:200; cat. no. ab32199; Abcam). The horseradish-peroxidase conjugated secondary antibody was goat anti-rabbit IgG (1:2,000; cat. no. sc-2040; Santa Cruz Biotechnology, Inc., Dallas, TX, USA), which was used at 1:200. Hematoxylin was used to counterstain nuclei at room temperature for $3 \mathrm{~min}$. Subsequently, images captured from 3-5 fields of view with the magnification of $x 400$ from each sample were analyzed under the light microscope. Samples with $>10 \%$ positive cells were considered positive. The negative control for this experiment was sections incubated without primary antibody and the indicated antibodies were tested in the positive control samples according to the protocols provided by the manufacturer (anti-PPAR- $\gamma$ antibody, cat. no. ab209350; anti-PTEN antibody, cat. no. ab32199; Abcam). The microscopes and imaging system, Leica Microsystems GmbH (Wetzlar, Germany), was used for analysis, and positive rates were analyzed. Grey levels were analyzed automatically for IHC paraffin blocks. In the grey level analysis, the level is negatively correlated with the expression level of proteins. The detailed methods used are as reported previously (12). In this method, low expression is reported as a high grey level, and high protein expression is reported as a low grey level. The grey level data are presented in the results.

Statistical analysis. All data were analyzed using SPSS software version 13.0 (SPSS, Inc., Chicago, IL, USA). Patient parameters are presented as the mean \pm standard error of the mean for each characteristic. Pearson correlation analysis was used to determine the coefficient of association between clinical characteristics and PPAR- $\gamma$ or PTEN. The Kruskal-Wallis test was used to analyze the enumeration data. Measurements between different groups were statistically analyzed using a two-tailed Student's t-test. $\mathrm{P}<0.05$ was considered to indicate a statistically significant difference.

\section{Results}

Bioinformatics analysis reveals distinct expression patterns of PPAR- $\gamma$ and PTEN in bladder cancer. As presented in Fig. 1, PTEN expression in bladder cancer is highest among the cancers examined. PTEN expression was significantly reduced in prostate and liver cancers compared with normal tissues $(\mathrm{P}<0.001)$, although in bladder cancer, it was significantly increased compared with normal tissue $(\mathrm{P}<0.001)$. PPAR- $\gamma$ expression was downregulated in bladder $(\mathrm{P}<0.05)$ and prostate $(\mathrm{P}<0.001)$ cancers. In renal and liver tumors, PPAR- $\gamma$ expression increased $(\mathrm{P}<0.001)$. Therefore, heterogeneity among different cancers was observed for PPAR- $\gamma$ and PTEN expression. 


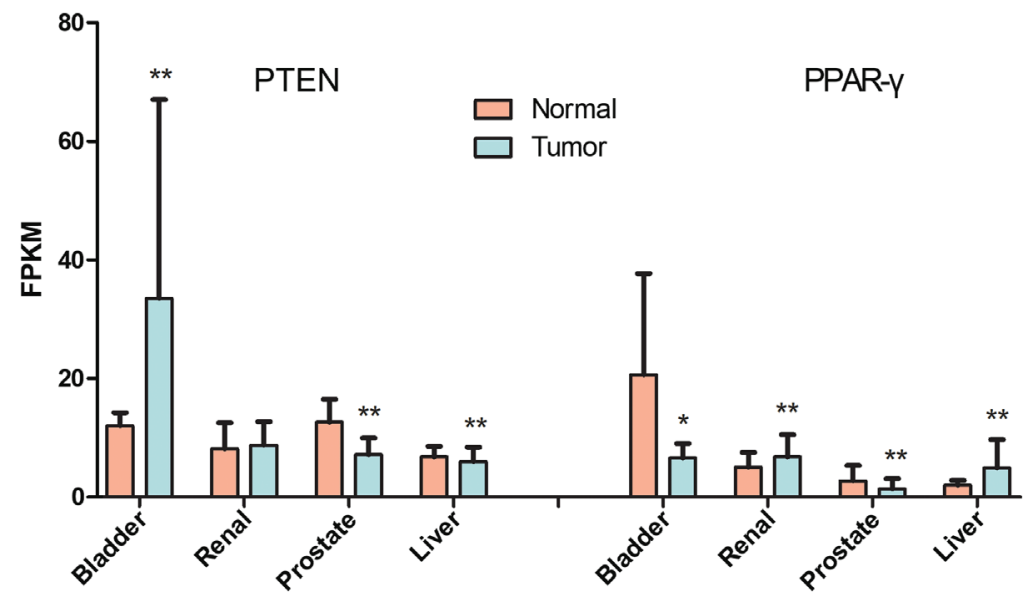

Figure 1. PTEN and PPAR- $\gamma$ RNA levels in different tissues according to the analysis of The Cancer Genome Atlas database. PTEN expression in bladder cancer is the highest among the cancers examined. In bladder cancer, it was significantly increased compared with normal samples. PPAR- $\gamma$ expression was downregulated in bladder and prostate cancers, compared with respective healthy samples. In renal and liver tumors, PPAR- $\gamma$ expression was significantly increased. ${ }^{*} \mathrm{P}<0.05$ and ${ }^{* *} \mathrm{P}<0.01$ vs. normal. PPAR- $\gamma$, peroxisome proliferator-activated receptor- $\gamma ; \mathrm{PTEN}$, phosphatase and tensin homologue deleted on chromosome ten.

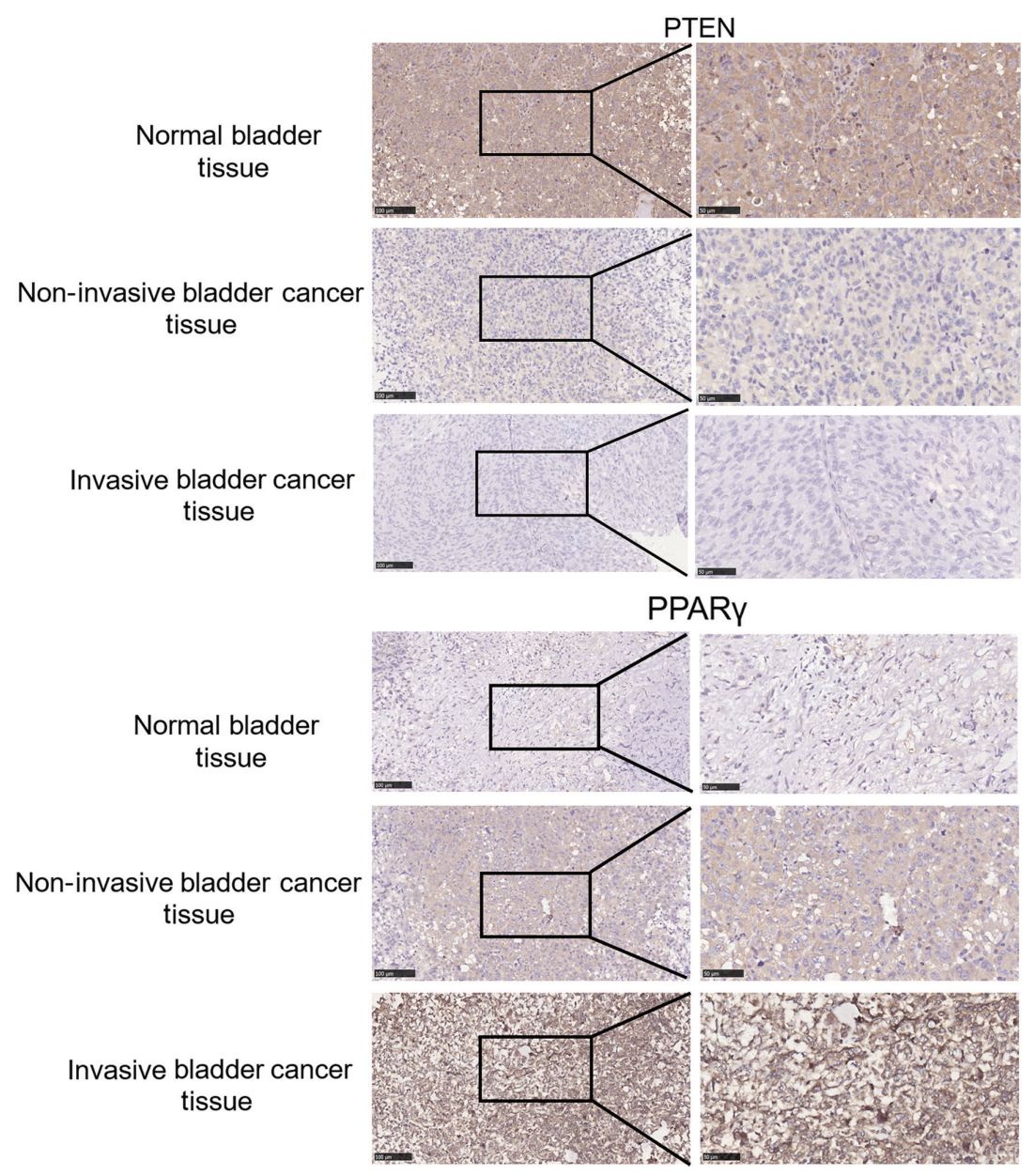

Figure 2. Varied expression of PTEN and PPAR- $\gamma$ in normal bladder tissues and bladder cancer tissues. The PTEN expression levels are significantly decreased during the generation and development of bladder cancer. The scale bar stands for $100 \mu \mathrm{m}$ in the left columns and $50 \mu \mathrm{m}$ in the right columns. PPAR- $\gamma$, peroxisome proliferator-activated receptor- $\gamma$; PTEN, phosphatase and tensin homologue deleted on chromosome ten.

Validation of PTEN and PPAR- $\gamma$ expression in clinical bladder cancer samples. IHC was used to evaluate PTEN and PPAR- $\gamma$ expression in paraffin slides from bladder cancer samples. As presented in Fig. 2, PTEN expression was reduced in bladder cancer tissue compared with normal tissues and was markedly decreased for the duration of cancer progression. PPAR- $\gamma$ levels were markedly increased in bladder cancers and increased as invasion and bladder carcinoma became more severe. Furthermore, it was concluded that PTEN and PPAR- $\gamma$ expression were markedly negatively associated in clinical samples. 
Table I. PTEN expression in bladder tissues.

\begin{tabular}{lrrrrr}
\hline & \multicolumn{2}{c}{$\begin{array}{c}\text { PTEN } \\
\text { expression (n) }\end{array}$} & & & \\
\cline { 2 - 5 } Group & + & - & PTEN positive rate (\%) & $\chi^{2}$ & P-value \\
\hline Normal bladder & 20 & 0 & 100 & 15.84 & $<0.0001$ \\
Bladder cancer & 49 & 45 & 50 & & \\
\hline
\end{tabular}

PTEN, phosphatase and tensin homologue deleted on chromosome ten.

Table II. PPAR- $\gamma$ expression in bladder tissues.

\begin{tabular}{lrrrrr}
\hline & \multicolumn{2}{c}{$\begin{array}{c}\text { PPAR- } \gamma \\
\text { expression (n) }\end{array}$} & & & \\
\cline { 2 - 5 } Group & + & - & PPAR- $\gamma$ positive rate (\%) & $\chi^{2}$ & P-value \\
\hline Normal bladder & 4 & 16 & 20 & 15.82 & $<0.0001$ \\
Bladder cancer & 64 & 30 & 68 & & \\
\hline
\end{tabular}

PPAR- $\gamma$, peroxisome proliferator-activated receptor- $\gamma$.

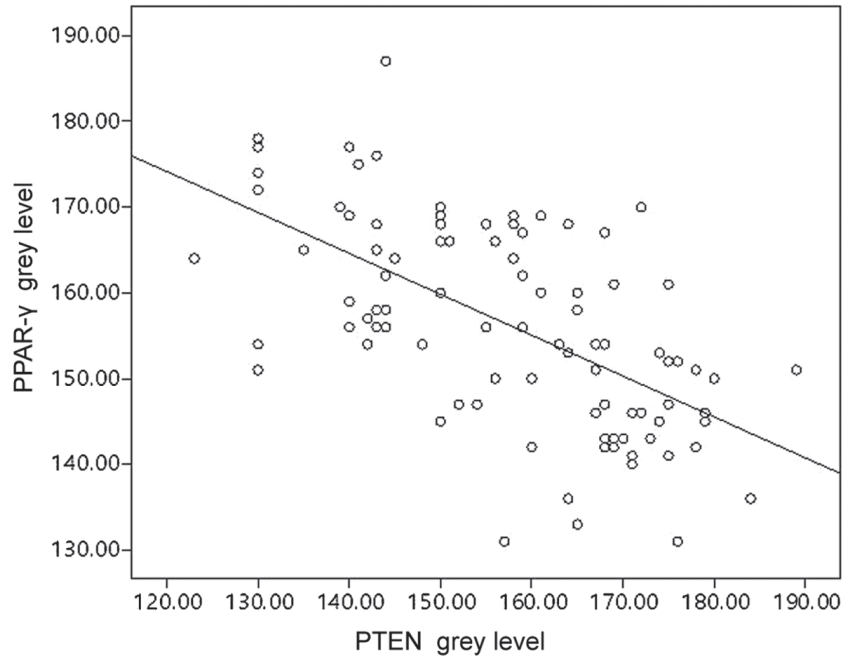

Figure 3. PPAR $-\gamma$ and PTEN levels in bladder cancers are significantly negative correlated $(r=-0.604 ; \mathrm{P}<0.05)$. PPAR $-\gamma$, peroxisome proliferatoractivated receptor- $\gamma$; PTEN, phosphatase and tensin homologue deleted on chromosome ten.

PTEN and PPAR- $\gamma$ levels are negatively correlated in bladder cancer. PTEN and PPAR- $\gamma$ expression were further analyzed in tissue samples from a cohort of patients with bladder cancer. PTEN expression was significantly lower in bladder cancer samples than in normal tissues $(\mathrm{P}<0.0001$; Table I). However, PPAR- $\gamma$ levels were significantly elevated in bladder cancer compared with normal tissues $(\mathrm{P}<0.0001$; Table II). To demonstrate the association between PTEN and PPAR- $\gamma$, scatter diagrams were used to indicate the distribution of biomarker expression, and Pearson correlation analysis was used to evaluate statistical significance. As presented in Fig. 3, a significant negative correlation was confirmed between PPAR- $\gamma$ and PTEN expression $(r=-0.604 ; \mathrm{P}<0.05)$. However, in other cancers, this association changed based on cancer type. Using data from the TCGA database (Fig. 4), PPAR- $\gamma$ and PTEN were positively correlated in liver $\left(\mathrm{r}^{2}=0.033 ; \mathrm{P}<0.001\right)$ and renal cancers $\left(\mathrm{r}^{2}=0.03 ; \mathrm{P}<0.001\right)$. In prostate cancer, there was no significant correlation between PPAR- $\gamma$ and PTEN expression. The bladder cancer data collected from the TCGA database, however, generated different results to those observed in the present clinical samples ( $\mathrm{P}=0.002$; Figs. 1 and 4$)$.

PPAR- $\gamma$ and PTEN are associated with bladder cancer progression. The mean age of the individuals that provided clinical samples was $71 \pm 11.22$ years with a range of 33-92 years. The PPAR- $\gamma$ grey level was significantly upregulated in tumor tissues $(189.55 \pm 6.85$ vs. $156.31 \pm 11.83$; $\mathrm{P}=0.002$; Table III) compared with normal bladder tissue. Notably, unlike renal cancer and colorectal cancer, bladder cancer tissue exhibited PTEN downregulation (133.00 \pm 7.69 vs. $157.3 \pm 14.98 ; \mathrm{P}=0.001$; Table III) $(13,14)$. Furthermore, although tumor size was not associated with expression, PPAR- $\gamma$ levels were higher in superficial bladder cancers than in invasive tumors (grey level, $162.26 \pm 9.40$ vs. $150.23 \pm 12.56$; $\mathrm{P}<0.01$ ), and PTEN was expressed at significantly lower levels in superficial bladder cancers than in invasive tumors (grey level $145.30 \pm 6.98$ vs. $170.61 \pm 8.88 ; \mathrm{P}<0.01)$. PPAR- $\gamma$ levels were also lower in low-grade bladder cancer samples than in high-grade cancer tissues (grey level $159.22 \pm 10.85$ vs. $151.40 \pm 11.94$; $\mathrm{P}=0.002$ ), whereas the opposite association was observed in the PTEN analysis (grey level $153.51 \pm 16.25$ vs. $163.91 \pm 9.67 ; \mathrm{P}=0.001$ ). The association between lymphatic metastasis and marker expression was also assessed and revealed that PPAR $-\gamma$ levels were elevated (grey level, 159.54 \pm 10.31 vs. 149.74 \pm 12.15 ; 

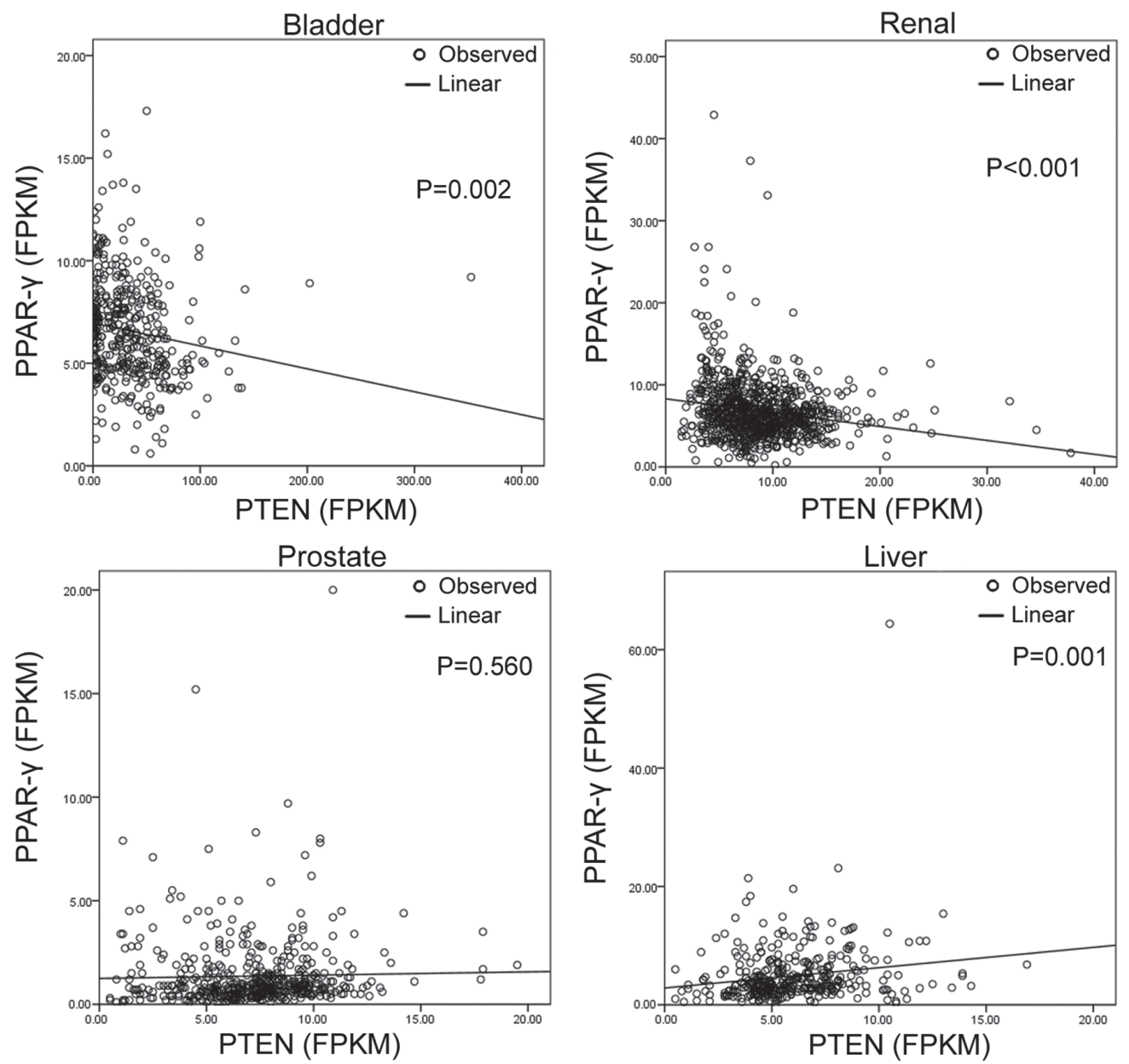

Figure 4. Association between PPAR- $\gamma$ and PTEN expression in different types of cancer collected from The Cancer Genome Atlas database. PPAR- $\gamma$ and PTEN were positively correlated in liver $\left(\mathrm{r}^{2}=0.033 ; \mathrm{P}<0.001\right)$ and renal cancers $\left(\mathrm{r}^{2}=0.03 ; \mathrm{P}<0.001\right)$. In prostate cancer, there was no significant correlation between PPAR- $\gamma$ and PTEN expression. PPAR- $\gamma$, peroxisome proliferator-activated receptor- $\gamma$; PTEN, phosphatase and tensin homologue deleted on chromosome ten; FPKM, fragments per kilobase of exon model per million mapped fragments

$\mathrm{P}<0.01)$ in patients without lymphatic metastasis, whereas PTEN levels were reduced (grey level, 153.90土15.63 vs. $164.45 \pm 10.66 ; \mathrm{P}<0.01$ ) in the same individuals. No significance was observed between marker expression and number of local tumors.

\section{Discussion}

In the present study, PTEN and PPAR- $\gamma$ expression was analyzed in bladder cancers and a negative correlation was demonstrated between them. This is the first time, to our knowledge, that this association has been documented in bladder cancer, which differs from other cancer types $(13,14)$. Furthermore, the association between PTEN and PPAR- $\gamma$ expression and bladder cancer progression was examined, revealing different expression correlations during bladder cancer development.

As one of the most common carcinomas of the urinary tract, bladder cancer is primarily $(>90 \%)$ a transitional cell carcinoma (15). Cystoscopy is a commonly used method that generates a diagnosis by the biopsy of suspicious lesions. The gold standard for diagnosis is a biopsy obtained during cystoscopy, during which cancer may be an incidental finding (16). In many cases, cystoscopy can overlook a tumor, particularly when it is small, and is also highly dependent on clinician skill (17). Therefore, biomarker identification is important for the diagnosis and prognosis of bladder cancer. Many limits and biases exist for single markers, highlighting the potential utility of a combination of biomarkers as an effective predictor of bladder cancer progression.

PPAR- $\gamma$ is widely known for its influence on metabolism and inflammation as well as its role in cell differentiation and apoptosis $(18,19)$. In addition, it has been studied in oncology, and a number of studies suggest that PPAR- $\gamma$ promotes cancer development and is highly expressed in urinary tumors $(20,21)$. In contrast, other studies have suggested that the activation of PPAR- $\gamma$ indirectly blocks carcinogenesis and aids in anticancer therapy $(22,23)$. Therefore, PPAR- $\gamma$ expression and function exhibits apparent tissue heterogeneity. Based on these findings, it was hypothesized that it may also be a biomarker for detecting early stage bladder cancer.

PTEN is important for cell growth and regulates metabolic processes, cell motility and polarity via the phosphoinositide 3-kinase (PI3K) pathway (24). Furthermore, PTEN also inhibits tumor angiogenesis through the PI3K/protein kinase B (AKT) pathway, which regulates vascular endothelial growth factor and its receptor as well as matrix metalloproteinases. PTEN mutations remove a contribution to the negative regulation of 
Table III. PPAR- $\gamma$ and PTEN grey level in bladder tissues according to different individual characteristics.

\begin{tabular}{|c|c|c|c|c|c|c|c|}
\hline Group & $\mathrm{n}$ & PPAR- $\gamma$ (grey level) & T-value & P-value & PTEN (grey level) & T-value & P-value \\
\hline Normal bladder & 20 & $189.55 \pm 6.85$ & 12.11 & 0.002 & $133.00 \pm 7.69$ & 7.06 & 0.001 \\
\hline Bladder cancer & 94 & $156.31 \pm 11.83$ & & & $157.30 \pm 14.98$ & & \\
\hline \multicolumn{8}{|l|}{ Tumor size $(\mathrm{cm})$} \\
\hline$\leq 3$ & 46 & $158.07 \pm 11.97$ & 1.42 & 0.160 & $155.48 \pm 16.06$ & 1.21 & 0.230 \\
\hline$>3$ & 48 & $154.63 \pm 11.57$ & & & $159.21 \pm 13.79$ & & \\
\hline \multicolumn{8}{|l|}{ Clinic grade } \\
\hline Superficial & 61 & $162.26 \pm 9.40$ & 9.92 & $<0.01$ & $150.23 \pm 12.56$ & 9.14 & $<0.01$ \\
\hline Invasive & 33 & $145.30 \pm 6.98$ & & & $170.61 \pm 8.88$ & & \\
\hline \multicolumn{8}{|c|}{ Pathological grade } \\
\hline Low grade & 59 & $159.22 \pm 10.85$ & 3.25 & 0.002 & $153.51 \pm 16.25$ & 3.89 & 0.001 \\
\hline High grade & 35 & $151.40 \pm 11.94$ & & & $163.91 \pm 9.67$ & & \\
\hline \multicolumn{8}{|c|}{ Lymphatic metastasis } \\
\hline No & 61 & $159.54 \pm 10.31$ & 4.08 & $<0.01$ & $153.90 \pm 15.63$ & 3.84 & $<0.01$ \\
\hline Yes & 33 & $149.74 \pm 12.15$ & & & $164.45 \pm 10.66$ & & \\
\hline \multicolumn{8}{|c|}{ Number of local tumors } \\
\hline Single & 47 & $157.85 \pm 11.27$ & 1.27 & 0.208 & $154.57 \pm 16.05$ & 1.84 & 0.069 \\
\hline Multiple & 47 & $154.77 \pm 12.30$ & & & $160.19 \pm 13.42$ & & \\
\hline
\end{tabular}

Data are presented as the mean \pm standard error of the mean. Grey level is negatively correlated with the protein expression. PPAR- $\gamma$, peroxisome proliferator-activated receptor- $\gamma$; PTEN, phosphatase and tensin homologue deleted on chromosome ten.

cell growth, leading to tumor development (25). PTEN has also been widely studied in the progression of prostatic, gastric, renal and breast cancer, among others, and is an important regulator and marker for carcinoma occurrence and development (20).

In the present study, PTEN and PPAR- $\gamma$ expression was analyzed in different tissues using TCGA. In the present analysis, PTEN expression was significntly elevated in bladder cancers, and PPAR- $\gamma$ was downregulated; the association of these two proteins varied across tumor type. Notably, PTEN and PPAR- $\gamma$ expression were positively correlated in prostate and liver cancer. Although a different view for PPAR- $\gamma$ and PTEN expression in renal clear cell cancer has been suggested, this discrepancy may be caused by differences in metabolic subtypes of cancer. Bladder cancer tissue from 94 clinical cases was included and different results to the TCGA data were obtained. This may be because the normal tissue and tumor data are collected from two different databases. Furthermore, there may be discrepancies between RNA level and protein expression as indicated in previous reports $(26,27)$.

Furthermore, PTEN and PPAR- $\gamma$ expression was significantly correlated with clinical stage and pathological progression, indicating that these molecules have potential as markers of bladder cancer tumorigenesis and development. Furthermore, Pearson analysis indicated that PTEN and PPAR- $\gamma$ expression was negatively correlated, which is distinct from the association observed in liver cancer. This association may be associated with tumorigenesis and progression. During colorectal carcinogenesis, PPAR- $\gamma$ and PTEN expression are positively correlated, which may indicate an interaction between these two proteins, with PTEN being a potential downstream regulatory factor of PPAR- $\gamma$ (13). However, the present results were not in accordance with those of a previous report (13). It is generally accepted that PPAR- $\gamma$ activates the expression of genes such as PTEN, c-myc and P27, which inhibit cancer proliferation, metastasis and invasion (28). It has been reported previously that after PPAR- $\gamma$ activation, PTEN expression is elevated in colorectal cancers (13), which contributes to phosphatidylinositol $(3,4,5)$-trisphosphate (PIP3) dephosphorylation, inhibiting the activation of PIP3 and PI3K/AKT signaling. Therefore, the cell cycle is generally blocked in the G1 stage, inhibiting proliferation and invasion (28). In the present study, however, PTEN expression was decreased, and PPAR- $\gamma$ was increased in bladder cancer tissue. First, although PPAR- $\gamma$ is highly expressed, its activation may not be elevated. Second, elevated expression may be a bladder cancer adaptation that ensures the ligand level is insufficient to generate an anti-tumor effect. Third, this may result from a PPAR- $\gamma$ mutation in bladder cancer, which requires validation. Finally, as PTEN and PPAR- $\gamma$ are both important metabolism markers, the variation observed may be caused by differences between the metabolic profiles of different cancers.

However, there are also limitations in the present study. Firstly, the patients are all from one hospital and further studies are required to confirm the effect of these markers. Secondly, more detailed molecular mechanisms should be further studied for PTEN and PPAR- $\gamma$ in bladder cancer. Thirdly, in order to detect bladder cancer more concisely, more markers should be supplied to this multifactorial analysis.

In conclusion, the present study suggests that PPAR- $\gamma$ and PTEN expression are closely associated with bladder cancer prognosis and are negatively correlated with each other. Therefore, PPAR- $\gamma$ and PTEN signaling may be a potential therapeutic target in bladder cancer. 


\section{Acknowledgements}

Not applicable.

\section{Funding}

The present study was supported by the Youth Project of Rejuvenating Public Health through Science and Education of Suzhou (grant no. KJXW2014023) and the Precision Medicine Program of Second Military Medical University (grant no. 2017JZ35).

\section{Availability of data and materials}

The datasets used and/or analyzed during the current study are available from the corresponding author on reasonable request.

\section{Authors' contributions}

$\mathrm{ZZ}$ and FW designed the study. HX and JJ wrote the manuscript. XS performed data collection. JL, YZ and HY performed statistical analysis. All authors read and approved the final manuscript.

\section{Ethics approval and consent to participate}

The present study was approved by Suzhou Municipal Hospital Ethics Committee. All patients provided written informed consent.

\section{Patient consent for publication}

Not applicable.

\section{Competing interests}

The authors declare that they have no competing interests.

\section{References}

1. Siegel RL, Miller KD and Jemal A: Cancer statistics, 2016. CA Cancer J Clin 66: 7-30, 2016.

2. Babjuk M, Burger M, Zigeuner R, Shariat SF, van Rhijn BW, Comperat E, Sylvester RJ, Kaasinen E, Böhle A, Palou Redorta J et al: EAU guidelines on non-muscle-invasive urothelial carcinoma of the bladder: Update 2013. Eur Urol 64: 639-653, 2013.

3. Strand DW, DeGraff DJ, Jiang M, Sameni M, Franco OE, Love HD, Hayward WJ, Lin-Tsai O, Wang AY, Cates JM, et al: Deficiency in metabolic regulators PPARgamma and PTEN cooperates to drive keratinizing squamous metaplasia in novel models of human tissue regeneration. Am J Pathol 182: 449-459, 2013.

4. Aboseif S, El-Sakka A, Young P and Cunha G: Mesenchymal reprogramming of adult human epithelial differentiation. Differentiation 65: 113-118, 1999.

5. Li Y, Liu W, Hayward SW, Cunha GR and Baskin LS: Plasticity of the urothelial phenotype: Effects of gastro-intestinal mesenchyme/stroma and implications for urinary tract reconstruction. Differentiation 66: 126-135, 2000.

6. Castillo-Martin M, Domingo-Domenech J, Karni-Schmidt O, Matos T and Cordon-Cardo C: Molecular pathways of urothelial development and bladder tumorigenesis. Urol Oncol 28: 401-408, 2010.

7. Michalik L, Auwerx J, Berger JP, Chatterjee VK, Glass CK, Gonzalez FJ, Grimaldi PA, Kadowaki T, Lazar MA, O'Rahilly S, et al: International union of pharmacology. LXI. peroxisome proliferator-activated receptors. Pharmacol Rev 58: 726-741, 2006
8. Krishnan A, Nair SA and Pillai MR: Biology of PPAR gamma in cancer: A critical review on existing lacunae. Curr Mol Med 7: 532-540. 2007.

9. Platt FM, Hurst CD, Taylor CF, Gregory WM, Harnden P and Knowles MA: Spectrum of phosphatidylinositol 3-kinase pathway gene alterations in bladder cancer. Clin Cancer Res 15: 6008-617, 2009.

10. Dormandy JA, Charbonnel B, Eckland DJ, Erdmann E, Massi-Benedetti M, Moules IK, Skene AM, Tan MH, Lefèbvre PJ, Murray GD, et al: Secondary prevention of macrovascular events in patients with type 2 diabetes in the PROactive Study (PROspective pioglitAzone Clinical Trial In macroVascular Events): A randomised controlled trial. Lancet 366: ,1279-1289, 2005.

11. Montironi R and Lopez-Beltran A: The 2004 WHO classification of bladder tumors: A summary and commentary. Int J Surg Pathol 13: 143-153, 2005.

12. Francisco JS, Moraes HP and Dias EP: Evaluation of the Image-Pro Plus 4.5 software for automatic counting of labeled nuclei by PCNA immunohistochemistry. Braz Oral Res 18: 100-1004, 2004

13. Lin MS, Huang JX, Chen WC, Zhang BF, Fang J, Zhou Q, Hu Y and Gao HJ: Expression of PPARgamma and PTEN in human colorectal cancer: An immunohistochemical study using tissue microarray methodology. Oncol Lett 2: 1219-1224, 2011.

14. Zhu C, Wei J, Tian X, Li Y and Li X: Prognostic role of PPAR-gamma and PTEN in the renal cell carcinoma. Int J Clin Exp Pathol 8: 12668-12677, 2015.

15. Chalasani V, Chin JL and Izawa JI: Histologic variants of urothelial bladder cancer and nonurothelial histology in bladder cancer. Can Urol Assoc J 3: S193-S198, 2009.

16. Walid MS and Heaton RL: Can posthysterectomy cystoscopy be utilized as a screening test for bladder cancer? Ger Med Sci 6: $13,2008$.

17. Lotan Y and Roehrborn CG: Sensitivity and specificity of commonly available bladder tumor markers versus cytology: Results of a comprehensive literature review and meta-analyses. Urology 61: 109-118, 2003.

18. Forootan FS, Forootan SS, Malki MI, Chen D, Li G, Lin K, Rudland PS, Foster CS and Ke Y: The expression of C-FABP and PPARgamma and their prognostic significance in prostate cancer. Int J Oncol 44: 265-275, 2014.

19. Fuentes E, Guzman-Jofre L, Moore-Carrasco R and Palomo I: Role of PPARs in inflammatory processes associated with metabolic syndrome (Review). Mol Med Rep 8: 1611-1616, 2013.

20. Lee C, Ramirez JA, Guitart J and Diaz LK: Expression of cyclooxygenase- 2 and peroxisome proliferator-activated receptor gamma during malignant melanoma progression. J Cutan Pathol 35: 989-994, 2008.

21. Yoshimura R, Matsuyama M, Segawa Y, Hase T, Mitsuhashi M, Tsuchida K, Wada S, Kawahito Y, Sano H and Nakatani T: Expression of peroxisome proliferator-activated receptors (PPARs) in human urinary bladder carcinoma and growth inhibition by its agonists. Int J Cancer 104: 597-602, 2003.

22. Li MY, Yuan H, Ma LT, Kong AW, Hsin MK, Yip JH, Underwood MJ and Chen GG: Roles of peroxisome proliferator-activated receptor-alpha and -gamma in the development of non-small cell lung cancer. Am J Respir Cell Mol Biol 43: 674-683, 2010.

23. Sullivan PF, Pedersen NL, Jacks A and Evengard B: Chronic fatigue in a population sample: Definitions and heterogeneity. Psychol Med 35: 1337-1348, 2005.

24. Song MS, Salmena L and Pandolfi PP: The functions and regulation of the PTEN tumour suppressor. Nat Rev Mol Cell Biol 13: 283-296, 2012.

25. Jiang BH and Liu LZ: PI3K/PTEN signaling in angiogenesis and tumorigenesis. Adv Cancer Res 102: 19-65, 2009.

26. Edfors F, Danielsson F, Hallstrom BM, Kall L, Lundberg E, Ponten F, Forsström B and Uhlén M: Gene-specific correlation of RNA and protein levels in human cells and tissues. Mol Syst Biol 12: 883, 2016.

27. Greenbaum D, Colangelo C, Williams K and Gerstein M: Comparing protein abundance and mRNA expression levels on a genomic scale. Genome Biol 4: 117, 2003.

28. Langle Y, Lodillinsky C, Belgorosky D, Sandes EO and Eijan AM: Role of peroxisome proliferator activated receptor-gamma in bacillus Calmette-Guerin bladder cancer therapy. J Urol 188: 2384-2390, 2012. 